\title{
Research on the incentive mechanism of young teachers' training in
}

\section{Local Colleges}

\author{
Dichen Shen \\ Jilin Agricultural University, Jilin, Changchun, 130118, China \\ 781911388@qq.com
}

Keywords: Local Colleges and universities, young teachers, training, incentive mechanism

\begin{abstract}
With the development of incentive theory, the incentive mechanism of foreign university teachers is mainly through the work design and to meet the needs of teachers to mobilize their enthusiasm, focusing on the study of effective incentives and measures. The research on the incentive mechanism of university teachers in foreign countries is mainly focused on: lifelong professor system, the research on the establishment of a flat incentive type university, the use of the reputation of the three aspects of the university teacher's incentive. Research on incentive mechanism of domestic study of college teachers is mainly on the introduction and evaluation of foreign scholar's research on incentive theory and foreign experience and practice, incentive mechanism, the incentive mode of study and research. On the basis of criticizing and inheriting the western theory, the researchers of our country combine the reality of the university to form some special incentive theories and opinions of the university teachers.
\end{abstract}

\section{Introduction}

Most colleges and universities in China in the late 1980s and early 1990s, started the teacher performance evaluation of management practice, generally on Teachers' implementation of the quota system, in the 21 st century, most of the school implemented the "on-demand Shegang, according to post employment, to the post fixed salary, excellent merit reward" as the main content of the reform of personnel distribution system in industry and trade. Evaluation of teacher performance become teachers to check perform job duties, cash post allowance, the formation of the incentive mechanism of a necessary and important means, but many schools are failing to implement carry out reach the designated position, habits to traditional management model formulated a set of standard to examine all teachers. The evaluation result is not ideal.

\section{Local colleges and universities young teacher training incentive mechanism problems}

The research in local colleges and universities in the training of young teachers as the breakthrough point, to young teachers' career satisfaction survey as the basis, in view of the young teachers in Colleges and universities of our country culture lack of macro planning and building a system to study the actual, combined with young teachers' career and life education demands determine the young teachers training target management system and evaluation system, application and young teachers career development and value realization related material and spiritual conditions as a means of behavior and emotion incentive, the final presentation training mode design for the young college teachers' professional development. The main research contents and the key problems to be solved are as follows: 
(1) Questionnaire design and Research on the structure, characteristics and training effect of the young teachers in local colleges and universities.

(2) With the help of SPSS statistical software, the influence factors of young teachers' professional status, career satisfaction, career expectation, value appeal and training motivation are analyzed.

(3) The formation of local colleges and universities young teachers training incentive mechanism construction oriented. The key point is: the internal and external professional influence factors of the young teachers in local agricultural universities.

Including young teachers training objectives management principles, training performance evaluation principles, and continuously improve the principles of improvement, career planning stage to enhance the principle of. Under the guidance of the corresponding principles to achieve the incentive mechanism of the corresponding strategy design, reflect the university teachers as the basis for the realization of the value of knowledge service employees.

\section{Local colleges and universities young teacher training incentive mechanism to solve the solution}

The subject of local colleges and universities young teacher faculty characteristics and occupational status research foundation of brother institutions existing training measures and content summary, and young teachers in Colleges and universities internal demand corresponding confirmed existing training mode, the lack of points. Combined with the university personnel system reform practice, pay full attention to the young teachers for the training and upgrading, suitable for the construction of various types of colleges and universities young teacher training incentive system, teacher training of the sustainable development of the human resources training connotation of mining, the training of young teachers of colleges and universities to the normal direction of the leading propulsion.

(1) The action research method, action research method is an actual to adapt to education reform within a small range of exploratory research methods for the young teacher training needs to be improved, relying on the reality of running schools in Jilin Agricultural University, the use of action tracking mode to solve the problem that does not match the development of young teachers and the corresponding training. Research group is specialized is engaged in the human resources management and teacher training of personnel, responsible for in the project implementation process will be the reform of personnel system reform and the research work combined, in practice and constantly modify, topic of empirical research and model construction to enhance the ability of.

(2) Investigation method and comparative method combined by research group focuses on the design of the questionnaire, on College Young Teachers' occupational status, satisfaction, training demands, professional growth expectations research, for college teachers and training management personnel discussion, analysis of the actual situation of the school, analysis of data using SPSS software. Compared with the actual situation of the agricultural colleges and universities in the area, the data samples that can represent the young teachers are summarized, and the incentive measures and the implementation plan for the training of young teachers are summarized.

(3) Literature research method: by referring to the paper in the literature, literature database, education teaching files, listen to the recording of literature research, by means of collection of agricultural colleges and universities teaching system construction and data, comprehensively and correctly understand the research content, for young teachers in agricultural colleges and Universities Culture Studies provide objective reference and make more scientific research and design. 


\section{Summary}

In college teachers, young teachers is a active force, is an important force in the school teaching, research, administration, they have the unique needs of young people. A correct understanding of the needs of young teachers, grasp this important group under the new situation of ideological trends, establish and improve the corresponding incentive mechanism, to better promote the healthy development of young teachers, administrators in Colleges and universities, the university human resources management departments need to seriously study the solution of an important topic. Only with a full understanding of the needs of young teachers, from the people-oriented concept of the management of young teachers into the orbit of the management of colleges and universities, establishing proper incentive mechanism on the basis of this, achieve full excitation, the whole motivation, adhere to teachers as the main body, leading to motivate, effective use of incentive means, in order to maximize mobilize the enthusiasm of young teachers. This is also the effective measures to improve the management of school leaders. It is an effective way to improve the quality of teaching and scientific research, and to improve the efficiency of management, to implement the incentive mechanism to meet the needs of teachers.

\section{Acknowledgements}

This work was supported by Research on the educational reform of higher education in the Education Department of Jilin province in 2015: The Study on the incentive mechanism of young teachers' training in local colleges (2015-11)".

\section{References}

[1] Zhang Yao. A discussion on the construction of the system of incentive mechanism of university teachers [J]. Science and technology information development and economy, 2008, No.19316:187-189.

[2] Song Zhenhua. Study on the incentive mechanism of university teachers [D]. Kunming University of Science and Technology, 2004

[3] Yao Lihua. Study on the incentive mechanism of young teachers in Colleges and universities [D]. Tianjin University, 2009

[4] Ling Honglei. To establish and perfect the incentive mechanism of China's College Teachers' research [D]. Northwestern University, 2008

[5] Li Wenrong, Chen Xia, Li Yongzhong, Li Xiongping, Li Shijun. Study on the current situation, problems and Countermeasures of University Teachers' salary incentive mechanism [J]. agricultural education research, 2009, No.5801:26-28.

[6] Yang Shichen. Study on the incentive mechanism of university teachers [D]. Harbin Engineering University, 2006

[7] Jiang Hua. An Empirical Study on the satisfaction degree of teachers' compensation in art colleges in Hunan province [D]. Central South University, 2009

[8] fallout. Chongqing City College Political Instructors' Incentive of [D]. Chongqing Normal University, 2012

[9] Lina Ouyang. Study on performance evaluation system of basic level Party school [D]. Inner Mongolia University, 2012

[10] Shi Anling. Longqiao College Teachers Incentive Mechanism Research of [D]. Lanzhou University, 2008 